\title{
EDITORS’ INTRODUCTION
}

It is with great pleasure that the editors of the Journal of Arabic and Islamic Studies dedicate articles from volume 8 to Michael G. Carter on the occasion of his 70th birthday on 7 January 2009. While this does not pretend to be a Festschrift ${ }^{1}$ - nor was it conceived as such - the editors, together with Gunvor Mejdell of the University of Oslo, mentioned to friends and colleagues the possibility of submitting research articles in honour of Mike. Many willingly did so and we are appreciative to all those who have made contributions.

One major reason for this dedication is to pay tribute to Mike's longstanding role on the editorial board and as editor of the Newsletter of the Union Européenne des Arabisants et Islamisants, an association the academic values of which this journal has sought to promote since it was started in 1995 by Joseph Bell and Petr Zemánek. Both authors and editors of the journal have benefitted from the scholarly insights and wise counsel provided by Mike, whose point of departure for exploring the whole breadth and wealth of Arabic and Islamic culture has been Arabic grammatical theory with all its logical and theological complexities. Indeed, many contributors have put to good use Mike's constructive and anonymous advice which they received on submission of the first draft of an article.

The updated bibliography in this volume testifies to his unbroken productivity, but should be considered as only a scholarly Zwischenbilanz. We look forward to many further publications by the scholar honoured here. In these endeavours, as well as in all other aspects of his life, we wish him the very best.

\author{
Alex Metcalfe \\ Joseph Norment Bell \\ Lutz Edzard
}

\footnotetext{
1 Independent of any round anniversary, a volume comprising articles on grammatical theory was dedicated to Michael G. Carter in 2006: Grammar as a Window onto Arabic Humanism. A Collection of Articles in Honour of Michael G. Carter, edited by Lutz Edzard and Janet Watson. Wiesbaden: Harrassowitz.
} 